\title{
2 \\ Public good and private benefits of higher education
}

\author{
Martin Hall
}

\section{Introduction}

ver the last few decades levels of participation in higher education
have risen sharply in many parts of the world. This in turn has
prompted a shift from public funding to an expectation that students and their families should bear a greater proportion of the cost of a university education (Johnstone and Marcucci, 2010). As public policies have been shaped accordingly, this often-contested shift has come to be characterised as a distinction between the public good and the private benefits of education. On the one side of the scale, public goods are seen as the general benefits of a more highly skilled workforce, the advancement of qualities such as democracy and citizenship, and personal development. Weighing against this are the private benefits, which are almost invariably cast in terms either of entry into high status professional employment or as comparatively high earnings, expressed as a 'graduate premium'. In its most instrumental form, the return on the financial investment in university fees is compared favourably with the long-term return that a comparable investment in the stock market would bring.

This tussle between advocates of public goods and private benefits engages with the key issue of inequality and its consequences. In many parts of the world, profound socio-economic inequalities structure educational opportunity from the earliest years of education, whether in the United States, the United Kingdom or South Africa. Considered in terms of family incomes, the 
UK and the US are the most unequal of the developed economies - and these levels of inequality are growing.

This chapter explores some of the consequences of inequality for higher education policy and practice. Universities play an ambiguous role here. On the one hand, they operate as gatekeepers, ensuring access to symbolic capital that interprets higher education qualifications as positional goods, in danger of being valued more for the status they confer than for the value they add. But on the other hand, access to higher education contributes to breaking the bonds of poverty traps - self-reinforcing combinations of factors that perpetuate inequality (Hall, 2012).

When the issue of the appropriate balance between the public good of higher education and its private benefits is set against the enduring crises of inequality, some of the general assumptions that drive public policy development seem less secure. Inequality has deleterious consequences for the wellpaid (Wilkinson and Pickett, 2009), which suggests that elites benefit from investment in the public good to a far greater extent than is acknowledged in narrow concepts of a graduate premium. As participation rates continue to increase, graduate benefits show evidence of declining which also brings into question policies based on market models. In turn, growing doubts that possession of a degree guarantees secure, premium employment, direct attention to the inherent qualities of higher education and new ways of understanding private benefits.

\section{Inequalities}

Equality of opportunity is often stated as a self-evident, primary value. It is also frequently assumed that it is a condition easily established and verified. In today's debates about higher education admissions, it may be stated that there is equality of opportunity for any applicant for a place at a university, regardless of their financial circumstances, as long as appropriate, meanstested bursaries are available. An athletic metaphor is often used. Whatever their circumstances, it is claimed, the playing field is level if all applicants wrote the same final examination paper at secondary school.

At the same time, however, pronounced inequalities in life circumstances household income, employment opportunities, health, housing, education, life expectancy - are increasingly being seen as inevitable. Measured in terms of household income, South Africa is one of the most unequal countries in the world, with the gap between the poorest and the wealthiest deciles increasing steadily over the past two decades. Measured in the same way, 
Britain and America are the most unequal of the highly industrialised economies; in these countries also, inequality in household incomes has been increasing. Given the close link between attainment in education and household circumstances, the assumption that there is meaningful equality of opportunity in countries such as Britain, South Africa and the United States is dangerous.

Just as the meaning of equality of opportunity is easy to assume but far more difficult to apply, so the concept of inequality can be understood in various ways. It evidently has a good deal to do with money, but how wealth is measured and reported can vary hugely. Similarly, inequality can be experienced through lack of access to other tangible resources as well as to intangible qualities of life. Amartya Sen has been widely influential in his insistence that our understanding of inequality is extended beyond simple monetary indexes, taking into account what a person is able to do and be through the 'capabilities of persons to lead the kind of lives they value - and have reason to value' (Sen, 1999:18).

Patterns of inequality have a direct effect on children, and thus on education policy and education institutions. This is accentuated by demographic structures. In Britain, the median age is 40 years. Just over seventeen per cent of the population is below the age of fifteen. But in South Africa the median age is 25 and almost 30 per cent of the population is below the age of fifteen (see www.index mundi.com). Given the high levels of household poverty this situation could have disastrous consequences.

Patterns of achievement in the high school matriculation examination testify to this concern. The examination performs a similar function to British GCSEs, A-levels and vocational qualifications in managing the interface between school and employment, further and higher education. In 2007 just under one million young South Africans in the age cohort were expected to write the matriculation examination, 83 per cent of whom were African and seven per cent white. Thirty-five per cent of the African candidates and 64 per cent of the white candidates wrote the examinations and passed. Of these, 34 per cent of the white candidates achieved an endorsement: the minimum grades in specified combinations of subjects to be eligible to apply for higher education. By contrast, only 6 per cent of African candidates achieved an endorsement. In South Africa, an A-aggregate is required for the most selective university programmes such as medicine. One in 11 white candidates achieved an A-aggregate. This was matched by just 1 in 640 African candidates (Servaas van der Berg, University of Stellenbosch, personal communication). 
The South African limit case suggests that factors such as household income, unemployment, race and low levels of educational attainment are mutually reinforcing. While there will always be exceptional individuals, it would be futile to propose to the large majority of young South Africans, living with negligible household incomes, no opportunities for employment and no access to schools with any history of educational entertainment, that they should pull themselves up by their bootstraps, Horatio Alger style, and all will be well. Poverty and inequality are clearly part of a syndrome that needs to be understood and analysed as such.

One approach to understanding situations such as these is the concept of the 'poverty trap'. Here, Bowles et al draw a distinction with what they term the 'achievement model of income determination' - the assumption that the individual controls their economic destiny. Their approach is rather to look for mechanisms that could cause poverty to persist either in whole economies or in subgroups within economies (Bowles et al, 2006). Looked at in this way, South Africa's education system is an institutional poverty trap. The post-apartheid settlement created a complex set of interests that, over some two decades, has perpetuated a trend of increasing and extreme inequality. While a minority across all race categories has benefited from this, a large majority is 'stuck' in a cycle of unemployment, very low household incomes and little access to educational opportunity. These people are the direct descendants of those most discriminated against by apartheid laws. They are overwhelmingly young, and without any evident prospects. Mutually reinforcing factors - poverty traps - militate strongly against their breaking out of inter-generational poverty and inequality - and educational opportunities, from early schooling to higher education, are of central significance.

\section{Universities}

Access to different levels of education runs through all considerations of inequality, poverty and poverty traps. Evidently, access to education provides opportunities for individuals in their lifetimes. It is also a primary mechanism for inter-generational economic and social change. The concern here is with higher education as one part of a spectrum of provision and with universities as institutions.

While universities have an avowed progressive role, providing educational opportunities on the basis of neutral measures of merit, their role is also inherently ambiguous. Although they certainly provide life changing opportunities, they also serve as gatekeepers that maintain difference by exclusion and ranking, and contribute to enduring inequalities. This dual role is well 
understood from Pierre Bourdieu's compelling sociology of education in France, initially in the mid-1960s and then twenty years later (Bourdieu and Passeron, 1977; Bourdieu, 1996).

Bourdieu showed how selection and categorisation work through the interactions between individual applicants and institutional processes: 'disciplines choose their students as much as students choose their disciplines, imposing upon them categories of perception of subjects and careers as well as of their own skills' (1996:19). The result is that the university, 'with no explicit instructions ... is able to function like an immense cognitive machine, operating classifications that, although apparently completely neutral, reproduce pre-existing social classifications' (ibid:52). There are always exceptions - some individuals defy the norm and break into elite institutions, while others do not achieve what is expected of them in terms of their social class. These exceptions support claims of a meritocracy. But rather than a level playing field, Bourdieu sees a competitive dash for the finishing line, the academic cursus, 'that strange racecourse in which everyone classifies and everyone is classified, and where the best classified become the best classifiers of those who will next enter the race' (Bourdieu, 1996:52). Bourdieu showed how this system of classification produced and reproduced what he termed a 'state nobility' - a self perpetuating concentration of symbolic capital (ibid:79).

For potential students from less privileged backgrounds, getting a degree and thus access to the symbolic capital the university confers - could represent a step-wise change in circumstances. A student from a black South African family, whose parents were denied the opportunity of education beyond the basic level because of apartheid legislation, will earn a significant amount more than their parents on graduation and employment. British men born in the 1950s who gained a higher education qualification earned on average twice as much as men without such qualifications after twenty years in the labour force (Wolf, 2002). In the US, the 'college premium' - the difference in median wage between those who do not have a higher education qualification and those who do - was 72 per cent in 2008 (Rajan, 2010:24). For such students inter-generational social mobility is unambiguous and will in all likelihood be linked to a graduate premium in earnings.

For students whose families are already in graduate-level occupations, however, the benefits of the graduate premium are less clear. In Britain, the Dearing Committee of Inquiry into Higher Education estimated that the rate of return for students' own investment in higher education was between 11 
and 14 per cent in real terms. However, the inquiry also estimated that the social return on investment, which calculates the value added in terms of productivity, was between 7 and 9 per cent, against a minimum guideline of a 6 per cent return for public investment (Wolf, 2002). Such figures are the result of the significant increase in participation in British higher education over the last 50 years being so heavily skewed towards middle class families, diluting the transformative benefits of inter-generational social mobility. Put another way:

University degrees are wonderful things; it is the arranging and valuing of them by hierarchy of institution that is problematic, when people study for the label, for the university brand, rather than actually to learn. Because there were so few of them, the forerunners of today's university graduates almost all became part of a tiny elite, governing others and being rewarded with riches as a result. Because there are so many more graduates now, only a very small minority of today's university graduates can become rich at the expense of others. (Dorling, 2010:16)

Although it was apparent since the mid-1990s that the rapidly increasing rates of participation in British higher education were markedly skewed, it is still widely assumed that the continuation of this expansion is both inevitable and desirable. As Alison Wolf put it in her iconoclastic study: 'questioning the automatic value of any rise in the education budget, it seems, places one somewhere between an animal-hater and an imbecile.' Is it plausible, Wolf asked, that education is functioning as something other than a measure of skills? 'Might education not be serving, essentially, as a simple way of ranking, screening and selecting people in a mass society (Wolf, 2002:xi, 29)?'

Wolf's argument is that for the majority of participants in higher education in highly industrialised economies, a higher education qualification is increasingly a 'positional good', whose greater value is for competitive success in the labour market than the inherent qualities a university education confers. Such a positional good might be essential whether or not it also brings a private financial benefit. For most professions, a degree is an entry requirement and a wide range of jobs are only open to graduates, whatever the remuneration. The increasing importance of the positioning power of a degree - equivalent to the significance of symbolic capital in Bourdieu's analysis - is itself a function of widening middle class participation in higher education:

At a certain point in what had been a steady, slow expansion, large numbers of people started to feel that they really had better get a degree, because not doing so would be such a bad move. The first wave set off another, and so on. 
And their parents were very likely to agree ... the question becomes less 'does a degree pay well?' than 'can I afford not to have one?' (Wolf, 2002:178-81)

Clearly, then, the need for public policies that address these changing circumstances is urgent. In broader terms, the limits of narrow, econometric assumptions are increasingly recognised. In particular, the World Bank's twenty-year series of Human Development Reports and debates about the value of absolute measures of poverty based on comparative price indices are leading this widening process of re-evaluation (Deaton, 2010). Another example is the report by the Commission on the Measurement of Economic Performance and Social Progress. Released in 2009, it examined the limits of GDP as an indicator of economic performance and social progress (Stiglitz et al, 2009: 9).

The foundation for a different approach to education, and part of a wider concern with issues of equality and inequality, was laid 30 years ago by Amartya Sen. Working within the frame of mainstream economics, Sen showed how neither the concepts of 'opulence' nor 'utility' were adequate in themselves as a theory of well-being. Opulence and utility approaches see either the narrow objective of increasing real income or the fulfilment of interests as both the driving force of development and the appropriate emphasis of public policy, and lead naturally to the assumption that education is a commodity best traded in a market. Sen argues instead for a focus on the 'capability to function' - what a person can do and be on 'the achievement of a person: what he or she manages to do or to be' (Sen, 1999:7). For Sen, access to education and the ability to realise its opportunities is an unqualified good.

Sen's approach has been further developed by Martha Nussbaum (Nussbaum, 1997; 2010). In contrast to Sen, Nussbaum insists on a specific list of 'central capabilities'. These belong 'first and foremost to individual persons and only derivatively to groups ... at times group-based policies (for example, affirmative action) may be effective instruments in the creation of individual capabilities, but that is the only way they can be justified.' Two of these central capabilities play an 'architectonic role' in organising others: affiliation and practical reason (Nussbaum, 2011:35).

Melanie Walker has built on the work of both Sen and Nussbaum to develop a first list of key capabilities and functionings for higher education (Walker, 2006). In addressing the pervasive challenges of inequality, Walker sees it as essential to move beyond 'fairness' - providing opportunity - to ensure that every individual in education has the capability of taking advantage of such 
opportunities. This requires a comparison of the experiences of students based on their own, valued, achievements.

Following Sen, a capability is understood as a potential functioning, and the relationship between a capability and a functioning as equivalent to the relationship between the opportunity to achieve and actual achievement. Thus, in the context of the objectives of widening participation in higher education, a school leaver may decide to become a plumber...

even though she has the required grades for university entrance: she has the capability to choose. But another working class student who does not have the

Practical reason

Educational resilience

Knowledge and imagination

Learning disposition

Social relations and social networks

Respect, dignity and recognition

Emotional integrity, emotions

Bodily integrity
Being able to make well-reasoned, informed, critical, independent, intellectually acute, socially responsible, and reflective choices

Being able to navigate study, work and life

Being able to gain knowledge of a chosen subject - disciplinary and/or professional - its form of academic inquiry and standards

Being able to have curiosity and desire for learning

Being able to participate in a group for learning, working with others to solve problems and tasks

Being able to have respect for oneself and for and from others, being treated with dignity, not being diminished or devalued because of one's gender, social class, religion or race, valuing other languages, other religions and spiritual practices and human diversity'

Being able to develop emotions for imagination. Understanding, empathy, awareness and discernment

Safety and freedom from all forms of physical and verbal harassment in the higher education environment

Figure 2.1: Capabilities for Higher Education (Walker, 2006:128) 
required grades and chooses plumbing, even though he would rather study engineering at university, does not have the same capability. On the surface, the two students would seem to have made the same decision not to go to university. If one were evaluating only functionings (becoming a plumber) we would view the situation the same. However, if we look at capabilities, we evaluate choices which for one of the students would have been different in other circumstances ... the first student has freedom and rationality; the second student has rationality in choosing plumbing but not accompanied by conditions of freedom ... our evaluation of equality must take account of freedom in opportunities as much as observed choices. (Walker, 2006:28-9. See also Unterhalter, 2003)

In developing a capabilities approach to higher education, Walker places emphasis on agency. This is particularly important for 'adaptive preferences' - situations where people learn not to want things because they are off-limits in terms of gender, race or class, which results in the internalisation of a second class status. In stressing the importance of agency, Walker shows how the capability approach can move beyond the limitations of the idea of habitus, and how it can be ruptured and reformed:

The capability approach offers us a means to analyse change over time, recognizing the interaction of the social and the individual and the social constraints on choice such that we might adapt to a given habitus, but also making the possibility for agency central and important. (Walker, 2006:59)

Her provisional list of eight key capabilities for higher education builds on Nussbaum's emphasis on practical reason, affiliation and emotions as central capabilities (Walker, 2006:128-9).

In her work Walker stresses the significant role that institutions - universities - have in providing the conditions that enable the development of capabilities and functionings in individuals. By developing Sen and Nussbaum's broader emphasis on education in this way, Walker builds a bridge between the individual habitus and institutional culture.

A number of studies have drawn out the rich benefits of understanding the complex interplay between personal circumstances and opportunity (Archer et al, 2003; Reay et al, 2005). Longitudinal biographies are of particular value, as the first outcomes from the Inventing Adulthoods project have shown. This work has followed the lives of 100 people, first interviewed in 1996 in four areas of England and Northern Ireland when they were aged between 11 and 17, and then again over the next decade. The four lives from this data set, examined in depth by Rachel Thomson, provide rich and nuanced understandings both of 
how education is perceived and experienced and of the intersection of family life and personal relationships, circumstances and opportunities and institutional resources and structures (Thomson, 2009). They illustrate Melanie Walker's point about the significance of individual agency and the ways it can rupture habitus. This perspective takes us far beyond the concept of education as market in which competing educational goods are weighed and assessed for their comparative value for money.

In their work with twenty students at the University of Cape Town, Bongi Bangeni and Rochelle Kapp have tracked the longitudinal experiences of young adults as they move through the successive years of undergraduate study and develop agency and identity. Of particular interest is the way Bangeni and Kapp explore the interplay between individual development and the formal curriculum and institutional culture of the university. This study works through the medium of a three year programme in academic writing for students whose first language is not English and who are studying in an English medium environment. The exercises in writing realise key capabilities of practical reason, educational resilience, knowledge, learning disposition and respect and recognition. Bangeni and Kapp write that 'our data show that changes in students' identities and roles over their undergraduate years are intricately related to social boundaries, their emotional responses to the (often traumatic) events in their lives' (2005:16). Their ability to participate in university life - to construct capabilities and realise functionings - was shaped by the double ambiguity between their place in university life and their changing relationship with home.

These personal stories are complex accounts of successes and failures. However, the educational gain - the realisation of capability as functioning - is evident. Here, Sisanda describes how her approach to argument construction shifted over the course of three years:

First year to me essays were about reporting what I have learnt which was obviously not a good idea ... Second year, to make things easier I told myself I will read and either support or critique the author in addition to reading ... In constructing my arguments [in third year], not only do I discuss and support/ critique the authors, I compare and differentiate their views to build on my own opinions and views that I include in the paper as some point of departure or recommendation. (Kapp and Bangeni, 2009:590)

And here is Andrew, from a socially and economically marginalised working class suburb of Cape Town, Afrikaans speaking, and the first in his family to attend university: 
In an unsolicited preamble to his reflection paper in his final year, Andrew wrote: '... I am in an academic discourse where it is required of one to act/or to be the discipline, this is what I have come to realize over these past years. It is one thing to be in the discipline and another 'to be' the discipline. And each day I find more and more evidence within myself that I am at that point where I moved from being in my discipline, to where I am my discipline. This is evident in my speech, thought, and ways I approach certain things, whether in academic or formal setting.' Andrew's analysis, as well as the language in which it is expressed, reflected a growing awareness that he was not only learning the skills and content of the discipline, but was also entering into new subjectivities. (Kapp and Bangeni, 2009:591)

\section{Conclusion}

Equality of opportunity is often stated as a self-evident, primary value. However the evidence for pronounced inequalities in life circumstances shows this to be a chimera. A significant factor in rising levels of inequality are the poverty traps; self-perpetuating factors such as household income, unemployment, race-based inequalities and low levels of educational attainment that reinforce one another. While these are more apparent in the South African limit case, they are in evidence in many parts of the world including Britain, where inequality continues to rise. Given this, educational opportunities, and the public policies that enable them, are critical. As Amartya Sen demonstrated, educational attainment enables poverty traps to be broken and inter-generational social and economic mobility (Hall, 2012).

It can justly be claimed that universities have played, and continue to play, a progressive role in contributing to educational attainment and its benefits. But, as Bourdieu showed us, universities are also inherently ambiguous, operating at the same time as gatekeepers that advantage and protect elites and their concentrations of symbolic capital. Taken in the context of the extensive increases in higher education participation over recent decades, this is leading to a complex set of circumstances in which the possession of a degree as a 'positional good' remains essential for access to high value segments of the labour market at the time when the 'graduate premium' - the lifetime earnings advantage of a graduate over a non-graduate - seems to be declining.

This hollowing out of the value of a university education - circumstances in which the brand and status of an institution becomes more important than any transformational benefits of university attendance - is mirrored in a broader, growing concern with more general econometric measures of the quality of life. The World Bank's emphasis on measures of human develop- 
ment that are far broader than indices dominated by income is well established; other studies and commissions have questioned the value of the use of GDP as a measure of national success and individual benefit. When overemphasis on such narrow indices drives public policy, the consequences may be damaging. The argument here is that higher education policies that fail to address inequality and its consequences, and that measure the benefits of higher education in narrow econometric terms based on the model of a financial market, are both damaging and at risk of implosion, as graduate earnings decline as an inevitable consequence of increasing rates of participation.

The foundation for a different approach to education, and part of a wider concern with issues of equality and inequality, was laid by Amartya Sen thirty years ago, and has been further developed by Martha Nussbaum and others. Here, Melanie Walker's provisional list of eight key capabilities for higher education is particularly valuable. Capabilities and functionings are a different sort of private benefit - they return to the transformative value of education, for the individual, for the community and for the general public good.

\section{References}

Archer, L, Hutchings, M and Ross, A (eds) (2003) Higher Education and Social Class: issues of exclusion and inclusion. London: RoutledgeFalmer

Bangeni, B and Kapp, R (2005) Identities in transition: shifting conceptions of home among 'Black' South African university students. African Studies Review 48(3) 1-19

Bourdieu, P (1996) The State Nobility: elite schools in the field of power. Cambridge: Policy Press Bourdieu, P and Passeron, J C (1977) Reproduction in Education, Society and Culture. London: Sage

Bowles, S, Durlauf, S and Hoff, K (eds) (2006) Poverty Traps. Princeton: Princeton University Press Deaton, A (2010) Price indexes, inequality, and the measurement of world poverty. American Economic Review 100(1) 5-34

Dorling, D (2010) Injustice. Why social inequality persists. Bristol: Policy Press

Hall, M (2012) Inequality and Higher Education: marketplace or social justice. London: Leadership Foundation for Higher Education

Johnstone, D and Marcucci, P (2010) Financing Higher Education Worldwide. Who pays? Who should pay? Baltimore: John Hopkins University Press

Kapp, R and Bangeni, B (2009) Positioning (in) the discipline: Undergraduate students' negotiations of disciplinary discourses. Teaching in Higher Education 14(6) 587-96

Nussbaum, M (1997) Cultivating Humanity: a classical defense of reform in liberal education. Cambridge: Harvard University Press

Nussbaum, M (2010) Not for Profit: why democracy needs the humanities. Princeton: Princeton University Press

Nussbaum, M (2011) Creating Capabilities. The human development approach. Cambridge: Harvard University Press 


\section{PUBLIC GOOD AND PRIVATE BENEFITS OF HIGHER EDUCATION}

Rajan, R (2010) Fault Lines: how hidden fractures still threaten the world economy. Princeton: Princeton University Press

Reay, D, David, M and Ball, S (2005) Degrees of Choice. Social class, race and gender in higher education. Stoke on Trent: Trentham Books

Sen, A (1987, 1999) Commodities and Capabilities. New Delhi: Oxford University Press

Stiglitz, J, Sen, A and Fitousssi, J P (2009) Report by the Commission on the Measurement of Economic Performance and Social Progress. Paris: Commission on the Measurement of Economic Performance and Social Progress

Thomson, R (2009) Unfolding Lives: youth, gender and change. Bristol: Policy Press

Unterhalter, E (2003) Crossing disciplinary boundaries: the potential of Sen's capability approach for sociologists of education. British Journal of Sociology of Education 24(5) 665-70

Walker, M (2006) Higher Education Pedagogies: a capabilities approach. Maidenhead: Open University Press

Wilkinson, R and Pickett, K (2009) The Spirit Level: why more equal societies almost always do better. London: Allen Lane

Wolf, A (2002) Does Education Matter? Myths about education and economic growth. London: Penguin 